\title{
Stereochemical Studies on Dihydrofurano-isoflavones
}

\author{
Satoshi Tahara, John L. Ingham* \\ and Junya Mizutani \\ Department of Agricultural Chemistry, Faculty of Agriculture \\ Hokkaido University, Kita-ku, Sapporo 060, Japan \\ * Phytochemical Unit, Department of Botany, University of \\ Reading, Whiteknights, P.O. Box 221, Reading \\ RG6 $2 A S$, England
}

Received August 8, 1986

\begin{abstract}
The stereochemistry of some dihydrofurano-isoflavones previously isolated from white lupin roots, or obtained following fungal metabolism of prenylated isoflavones, was investigated using CD spectroscopy. The osmate ester/pyridine complex of dextrorotatory lupinisoflavone A (1) exhibited a positive CD Cotton effect at $480 \mathrm{~nm}$, indicating a side-structure configuration ( $S$ at C$\left.2^{\prime \prime}\right)$, opposite to that of natural rotenone (9), which afforded a negative Cotton effect at $474 \mathrm{~nm}(R$ configuration at $\mathrm{C}-2^{\prime}$ on the side structure [ring E]). The stereochemistry of the laevorotatory luteone metabolite BC-1 (2) and lupinisoflavone D (4) (both $R$-configuration at C-2' ) was similarly determined after converting to the corresponding dehydrate (10) or trimethyl-dehydrate (1b, 10a).
\end{abstract}

The isoflavones, a group of natural products which appear to act as early intermediates in the biosynthesis of numerous other isoflavonoids (e.g., pterocarpans, coumestans and rotenoids), lack an asymmetric center in their basic $\mathrm{C}_{6}-\mathrm{C}_{3}-\mathrm{C}_{6}$ carbon skeleton. However, prenylation of 'simple' isoflavones followed by sidechain oxidation to yield, for example, dihydropyrano or dihydrofurano derivatives, is known to result in the formation of an asymmetric center in the side-structure portion of these 'complex' molecules.

Up to 1981 , only a dihydrohydroxypyranoisoflavone (mundulone from Mundulea sericea $a^{1)}$, and two dihydrofurano-isoflavones (erythrinin C from Erythrina variegata ${ }^{2}$ and glabrescione A from Derris glabrescens ${ }^{3)}$ ) had been reported to contain an asymmetric carbon in the side structure. ${ }^{4)}$ Recently, however, we described the isolation of a further six dihydrofurano-isoflavones, namely lupinisoflavone A (1), lupinisoflavone B [( \pm$)$-2], lupinisoflavone C (3), lupinisoflavone D (4), and lupinisoflavones E and F, from methanolic extracts of white lupin (Lupinus albus) roots. ${ }^{5)}$ In addition, a variety of di- hydrofurano-, dihydrohydroxypyrano- and 2,3-dihydroxy-3-methylbutyl-substituted isoflavones, all containing an asymmetric center, have also been identified as fungal metabolites of the prenylated isoflavones wighteone $\left.(5),{ }^{6}\right)$ luteone $(\mathbf{6}),{ }^{7)}$ licoisoflavone A $(7)^{8)}$ and $2^{\prime}$-hydroxylupalbigenin (8). ${ }^{9)}$ Apart from racemic lupinisoflavone B (2), the various dihydrofurano-isoflavones from both lupin roots and fungus (Aspergillus flavus and Botrytis cinerea) cultures were isolated in an optically active form.

In order to obtain information on the stereospecificity of dihydrofurano-isoflavone formation in lupin roots and by fungal hyphae, we examined the stereochemical properties of various dihydrofurano-isoflavones obtained from these two disparate sources. Treatment of alkenes with osmium tetroxide in the presence of pyridine has been shown to afford

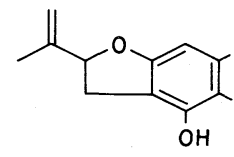

a

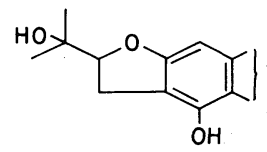

b 
pyridine adducts of the osmate esters which are non-planar, and which cause twisting of the associated five-membered rings. The CD $\left([\theta]_{\max }\right)$ sign of the curve given by these osmate esters between 470 and $480 \mathrm{~nm}$ can be correlated with the direction of the twist (see ref. 10 and citations therein). Thus, if an alkene contains an asymmetric center at the $\alpha$ - or $\beta$ position, its osmate ester is formed unequivalently in the direction of the twist as a result of stereo-inductive factors, ${ }^{11)}$ giving either a positive or negative $C D$ Cotton effect around $470 \sim 480 \mathrm{~nm}$. It has already been demonstrated that the stereochemistry of the isopropenyl-dihydrofurano side attachment a in certain 'complex' isoflavonoids can be readily determined by comparing the sign of the CD Cotton effect (at $c a .475 \mathrm{~nm}$ ) given by the osmate ester with that of natural rotenone (9), which contains the same part structure a and which is known from chemical ${ }^{12)}$ and crystallographic $^{13)}$ evidence to possess the $R$-configuration at the asymmetric center $\left(\mathrm{C}-2^{\prime}\right)$ in ring $\mathrm{E}$.

Thus, the stereochemistry of three pterocar- pan isoflavonoids (glyceollin $\mathrm{III},{ }^{14)}$ canescacarpin $^{15)}$ and apiocarpin ${ }^{16)}$ ) containing part structure a was recently established using this method. As isoflavones with the part structure b can be easily converted to those with a by $\mathrm{SOCl}_{2}$ dehydration, ${ }^{5)}$ it is clear that, like pterocarpans, these types of compound (e.g., 1 and 2) should also be amenable to the osmiun tetroxide stereostructure determination method. The optical rotation and CD data for a range of dihydrofurano-isoflavones and their derivatives are summarized in Table I.

The osmate ester/pyridine adduct afforded by dextrorotatory lupinisoflavone A (1, part structure a) gave a positive Cotton effect at $480 \mathrm{~nm}$, whereas that of rotenone with the $2^{\prime}$ $R$ configuration in ring $\mathrm{E}$ was negative $\left([\theta]_{474}=-5100\right)$. It follows, therefore, that the absolute stereochemistry of $\mathbf{1}$ is $2^{\prime \prime} S$.

After initial methylation, the laevorotatory Botrytis-derived luteone metabolite $\mathrm{BC}-1^{7)}(\mathbf{2}$, part structure b) was dehydrated as described in EXPERIMENTAL to give the corresponding trimethyl-dehydrate (1) $)$ as the major product. Derivative $\mathbf{1 b}$ was then converted into the

Table I. Optical Properties of Dihydrofurano-isoflavones

\begin{tabular}{|c|c|c|c|}
\hline Compound & {$[\alpha]_{\mathrm{D}}^{23}$ in $\mathrm{MeOH}$} & $\begin{array}{l}\text { CD: osmate ester } \\
{[\theta \theta]_{\max }^{23}(\mathrm{~nm})}\end{array}$ & Ref. \\
\hline Lupinisoflavone A (1) & $+74^{\circ}(c=0.11)$ & $+2100(480 \mathrm{~nm})$ & 5 \\
\hline Dimethyl-lupinisoflavone A (1a) & & $+3700(475 \mathrm{~nm})$ & 5 \\
\hline $\begin{array}{l}\text { Trimethyl-luteone metabolite BC-1 } \\
\text { dehydrate (1b) }\end{array}$ & $-63^{\circ}(c=0.10)$ & $-3500(475 \mathrm{~nm})$ & \\
\hline Luteone metabolite BC-1 (2) & $-100^{\circ}(c=0.11)$ & & $7^{a}$ \\
\hline Trimethyl-luteone metabolite BC-1 (2a) & $-83^{\circ}(c=0.16)$ & & \\
\hline Lupinisoflavone C (3) & $-60^{\circ}(c=0.11)$ & & 5 \\
\hline $\begin{array}{l}\text { Licoisoflavone A metabolite M-1-2 (4) } \\
\quad \text { from } A . \text { flavus cultures }\end{array}$ & $-77^{\circ}(c=0.12)$ & & 8 \\
\hline Lupinisoflavone D (4) & $-47^{\circ b}(c=0.10)$ & & 5 \\
\hline Rotenone (9) & & $-5100(474 \mathrm{~nm})$ & $14^{c}, 17^{d}$ \\
\hline Lupinisoflavone D dehydrate (10) & & $-2100(475 \mathrm{~nm})$ & 5 \\
\hline Trimethyl-lupinisoflavone D dehydrate (10a) & & $-2300(475 \mathrm{~nm})$ & 5 \\
\hline Wighteone metabolite Wi-1 (11) & $-112^{\circ}(c=0.07)$ & & 6 \\
\hline \multicolumn{4}{|l|}{ Licoisoflavone A metabolite M-2 (12) } \\
\hline from $A$. flavus cultures & $-65^{\circ}(c=0.11)$ & & 8 \\
\hline from $B$. cinerea cultures & $-57^{\circ}(c=0.11)$ & & 8 \\
\hline \multicolumn{4}{|l|}{ a See also the text. } \\
\hline \multicolumn{4}{|l|}{ b Partly racemized (?). } \\
\hline \multicolumn{4}{|l|}{ c Ref. $14,[\theta]_{474}-5800$} \\
\hline${ }^{d} \quad$ Ref. $17,[\theta]_{474}-5850$ & & & \\
\hline
\end{tabular}




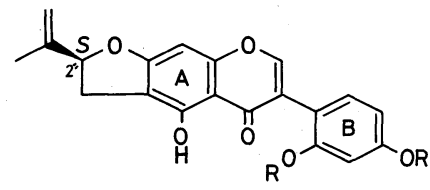

1: $\mathrm{R}=\mathrm{H}$; lupinisoflavone $\mathrm{A}$

1a: $\mathrm{R}=\mathrm{CH}_{3}$

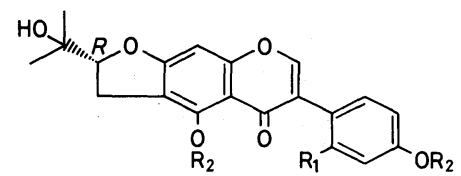

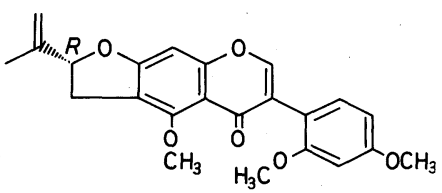

1b<smiles>[R]c1c(-c2coc3cc(O)cc(O)c3c2=O)ccc2c1CC(C)(C)O2</smiles>

2: $\mathrm{R}_{1}=\mathrm{OH}, \mathrm{R}_{2}=\mathrm{H}$; luteone metabolite $\mathrm{BC}-1$

3: $\mathrm{R}=\mathrm{H}$; lupinisoflavone $\mathrm{C}^{*}$

2a: $\mathrm{R}_{1}=\mathrm{OCH}_{3}, \mathrm{R}_{2}=\mathrm{CH}_{3}$

11: $R_{1}=R_{2}=H$; wighteone metabolite $\mathrm{Wi}-1$ *

4: $\mathrm{R}=\mathrm{OH}$; lupinisoflavone $\mathrm{D}$

(= licoisoflavone A metabolite M-1-2)<smiles>[R9]c1c(O)ccc(-c2coc3cc(O)c([R])c(O)c3c2=O)c1[R6]</smiles>

5: $\mathrm{R}_{1}=\mathrm{CH}_{2} \mathrm{CH}=\mathrm{C}\left(\mathrm{CH}_{3}\right)_{2}, \mathrm{R}_{2}=\mathrm{R}_{3}=\mathrm{H}$; wighteone

6: $\mathrm{R}_{1}=\mathrm{CH}_{2} \mathrm{CH}=\mathrm{C}\left(\mathrm{CH}_{3}\right)_{2}, \mathrm{R}_{2}=\mathrm{OH}, \mathrm{R}_{3}=\mathrm{H}$; luteone

7: $\mathrm{R}_{1}=\mathrm{H}, \mathrm{R}_{2}=\mathrm{OH}, \mathrm{R}_{3}=\mathrm{CH}_{2} \mathrm{CH}=\mathrm{C}\left(\mathrm{CH}_{3}\right)_{2}$; licoisoflavone $\mathrm{A}$

8: $\mathrm{R}_{1}=\mathrm{R}_{3}=\mathrm{CH}_{2} \mathrm{CH}=\mathrm{C}\left(\mathrm{CH}_{3}\right)_{2}, \mathrm{R}_{2}=\mathrm{OH}$;

2'-hydroxylupalbigenin<smiles>[R]Oc1cc([R])c2c(=O)c(-c3ccc4c(c3[R])CC(=C)O4)coc2c1</smiles>

10: $\mathrm{R}=\mathrm{H}$; lupinisoflavone $\mathrm{D}$ dehydrate 10a: $\mathrm{R}=\mathrm{CH}_{3}$<smiles>CC(C)(O)[C@@H]1Cc2c(O)ccc(-c3coc4cc(O)cc(O)c4c3=O)c2O1</smiles>

12: licoisoflavone A metabolite $\mathrm{M}-2 *$

FIG. 1. Structures of Dihydrofurano- and Other Complex Isoflavones Mentioned in the Text, and Rotenone.

* The stereochemistry of $\mathbf{3}, \mathbf{1 1}$ and $\mathbf{1 2}$ is inferred from the sign of optical rotation (see the text).

osmate ester to determine its CD spectrum. As shown in Table $\mathrm{I}$, the sign of the CD $(474 \mathrm{~nm})$ Cotton effect of $\mathbf{1 b}$ was negative, resembling that of the osmate ester of rotenone (9). This result indicates that both $\mathbf{9}$ and $\mathbf{1 b}$, and hence also the luteone metabolite BC-1 (2), have the same stereochemistry $(R)$ at the asymmetric carbon in their side structure.

The stereochemistry of a third dihydrofurano-isoflavone, laevorotatory lupiniso- 
flavone $\mathrm{D}^{5)}(4=$ licoisoflavone A metabolite M-1-2 ${ }^{8)}$ ), with part structure $\mathbf{b}$ attached to ring $B$ (rather than to ring $A$ as in 2), was similarly determined as described for $\mathbf{2}$. The osmate esters of the corresponding dehydrate $(\mathbf{1 0})^{5)}$ and trimethyl-dehydrate $(\mathbf{1 0 a})^{5)}$ gave $[\theta]_{475}=-2100$ and $[\theta]_{475}=-2300$, respectively. Again, the negtive sign of the CD Cotton effect demonstrates that these two compounds, and by implication the parent molecule 4, have the $R$-configuration at C- $2^{\prime \prime}$.

The results discussed above suggest that the side-structure stereochemistry of dihydrofurano-isoflavones may be deduced from their optical activity since laevorotatory compounds (2 and 4) exhibit the $2^{\prime \prime} R$ absolute configuration whereas that of dextrorotatory 1 is $2^{\prime \prime} S$. If this apparent correlation proves to be correct, the following structurally similar laevorotatory dihydrofurano-isoflavones (for which CD data are not available) must possess the side structure $\mathbf{b}$ with an $R$-configuration, a) the major compound (11, $[\alpha]_{\mathrm{D}}^{23}=-112^{\circ}$ ) resulting from metabolism of wighteone (5) by Botrytis cinerea ${ }^{6}{ }^{6}$ b) lupin-

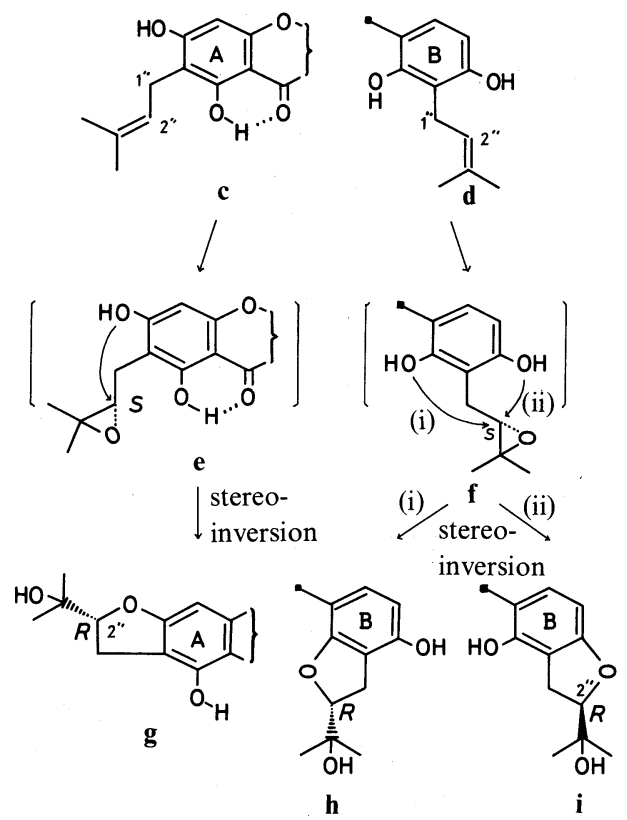

FIG. 2. Proposed Stereochemical Derivation of Dihydrofurano-isoflavones from Prenylated Precursors in Fungus Cultures and White Lupin Roots. isoflavone $C\left(3,{ }^{5)}[\alpha]_{D}^{23}=-60^{\circ}\right)$, and c) the licoisoflavone A metabolite M-2 (12) ${ }^{8)}$ isolated from cultures of Aspergillus flavus $\left([\alpha]_{\mathrm{D}}^{23}=\right.$ $\left.-65^{\circ}\right)$ and $B$. cinerea $\left([\alpha]_{\mathrm{D}}^{23}=-57^{\circ}\right)$. In addition to the observation that Aspergillus and Botrytis cultures yield laevorotatory 12, the fact that (-)-2" $R$-lupinisoflavone $\mathrm{D}$ (4) is produced by $L$. albus ${ }^{5)}$ and $A$. flavus (=the licoisoflavone A metabolite $\mathrm{M}-1-2^{8)}$ ) suggests that comparable stereospecific processes generally operate during dihydrofurano-isoflavone formation in both white lupin roots and fungus cultures.

In two earlier papers, ${ }^{7,8)}$ we suggested that fungal metabolism of prenylated isoflavones (with part structures $\mathbf{c}$ and d) might yield cyclic products via transitory epoxide intermediates (part structures e and $\mathbf{f}$ ). If this supposition is correct, the epoxides must presumably possess the $S$-configuration because, as illustrated in Fig. 2, formation of the dihydrofurano ring ( $R$-configuration, part structures $\mathbf{g}, \mathbf{h}$ and $\mathbf{i}$ ) is likely to result from $\mathrm{S}_{\mathrm{N}} 2$ attack of an orthophoenolic $\mathrm{OH}$ on $\mathrm{C}-2$ " coupled with stereoinversion.

Lupinisoflavone A (1) differs from the other four reported lupinisoflavones $(\mathrm{C} \sim \mathrm{F})$ in that it is dextrorotatory. Moreover, the present study has shown that in contrast to the $2^{\prime \prime} R$ absolute configuration of lupinisoflavone D (4) [and perhaps also lupinisoflavone C (3); see the text and Table I], the side structure stereochemistry of $\mathbf{1}$ is $S$. Amongst the naturally occurring isoflavonoids (pterocarpans) with a comparable part structure a, both apiocarpin $^{14)}$ and glyceollin III $^{16)}$ (from Apios tuberosa and Glycine max, respectively) have been shown to possess the identical $S$-configuration, whilst the opposite $R$-stereochemistry is associated with canescacarpin ${ }^{15}$ ) from $G$. canescens.

\section{EXPERIMENTAL}

General procedures (e.g., silica gel PTLC, and UV, MS and ${ }^{1} \mathrm{H}$-NMR measurements) were undertaken using the equipment and conditions described in our earlier papers. ${ }^{5,18)}$ 
Sources of isoflavones used in the present study. Lupinisoflavone A (1), lupinisoflavone D (4), lupinisoflavone $\mathrm{D}$ dehydrate (10) and trimethyl-lupinisoflavone D dehydrate (10a) were available from our previous investigation. ${ }^{5)}$ The luteone metabolie BC-1 (2) was re-isolated from luteone-metabolizing cultures of Botrytis cinerea, ${ }^{7)}$ and then converted into the corresponding trimethyl ether and dehydrate as subsequently described.

Luteone metabolite $B C-1$ (2). ${ }^{7)}$ Additional data for 2 : $[\alpha]_{\mathrm{D}}^{23}=-100^{\circ}(c=0.11, \mathrm{MeOH}$. In ref. 7 , we incorrectly reported the specific rotation of $\mathrm{BC}-1$ as $-10.6^{\circ}$ ).

Methylation of luteone metabolite BC-1 (2). The metabolite $(2,27 \mathrm{mg})$ was dissolved in $10 \mathrm{ml}$ of acetone, and was then refluxed for $2 \mathrm{hr}$ in the presence of dimethyl sulfate $(0.25 \mathrm{ml})$ and anhydrous $\mathrm{K}_{2} \mathrm{CO}_{3}(0.8 \mathrm{~g})$. After adding more dimethyl sulfate $(0.25 \mathrm{ml})$ and $\mathrm{K}_{2} \mathrm{CO}_{3}(0.8 \mathrm{~g})$, refluxing was continued for a further $2 \mathrm{hr}$, at which point the process was repeated to give a total refluxing time of $c a$. $6 \mathrm{hr}$. The reaction mixture was then worked-up in the usual manner, ${ }^{5)}$ and purified by PTLC $\left(\mathrm{CHCl}_{3}\right.$ : EtOAc: acetone: $\mathrm{MeOH}=50: 5: 5: 1)$ to yield $22 \mathrm{mg}$ of trimethylBC-1 (2a, $R f 0.40)$ and $3.6 \mathrm{mg}$ of dimethyl-BC-1 (Rf 0.69). The presence, in the latter compound $\left(\mathrm{M}^{+} 398\right)$, of an unmethylated $\mathrm{H}$-bonded (C-5) $\mathrm{OH}$ group was readily apparent from a) the bathochromic shift $(11 \mathrm{~nm})$ of the major $\mathrm{MeOH}$ maximum $(262 \mathrm{~nm})$ caused by the addition of $\mathrm{AlCl}_{3}$, and $\mathrm{b}$ ) the slow development of a blue-green color on chromatograms sprayed with a $\mathrm{CHCl}_{3}$ solution of Gibbs reagent and then exposed to $\mathrm{NH}_{3}$ vapor. ${ }^{5}$

Dimethyl-BC-1. Colorless gum, Gibbs test $(+)$, slow, blue-green. MS $m / z(\%): 399\left(\mathrm{M}^{+}+1,27\right), 398\left(\mathrm{M}^{+}, 100\right)$ $365\left(\mathrm{M}^{+}-33,40\right), 340(43), 339\left(\mathrm{M}^{+}-59,90\right), 309$ (14), 237 (13), 179 (15), 162 (15), 161 (23), 69 (15), 59 (43). UV $\lambda_{\max }^{\mathrm{MeOH}} \mathrm{nm}: 214,262,285 \mathrm{sh} ;+\mathrm{NaOMe}, 263,285 \mathrm{sh}$; $+\mathrm{AlCl}_{3}, 217,273,319,368$; unchanged with NaOAc. ${ }^{1} \mathrm{H}-$ NMR $\delta_{\text {TMS }}^{\text {acetone- } d_{6}}(100 \mathrm{NHz}): 1.25$ and 1.29 (both $3 \mathrm{H}$, two s, $4^{\prime \prime}$ - and $5^{\prime \prime}-\mathrm{H}_{3}$, 3.17. (2H, d-like, $J=8.3 \mathrm{~Hz}, 1^{\prime \prime}$ $\mathrm{H}_{2}$ ), 3.79 and 3.85 (both $3 \mathrm{H}$, two s, $\left.2 \times \mathrm{OCH}_{3}\right), 4.84(1 \mathrm{H}$, $\left.\mathrm{dd}, J=9.0,8.1 \mathrm{~Hz}, 2^{\prime \prime}-\mathrm{H}\right), 6.38(1 \mathrm{H}, \mathrm{s}, 8-\mathrm{H}), 6.57(1 \mathrm{H}, \mathrm{dd}$, $\left.J=8.3,2.4 \mathrm{~Hz}, 5^{\prime}-\mathrm{H}\right), 6.64\left(1 \mathrm{H}\right.$, incomplete d, $\left.3^{\prime}-\mathrm{H}\right), 7.23$ $\left(1 \mathrm{H}, \mathrm{d}, J=8.3 \mathrm{~Hz}, 6^{\prime}-\mathrm{H}\right), 8.04(1 \mathrm{H}, \mathrm{s}, 2-\mathrm{H}), 13.25$ (s, 5$\mathrm{OH})$.

Trimethyl-BC-I (2a). Colorless gum, Gibbs test $(-),[\alpha]_{\mathrm{D}}^{23}$ $-83^{\circ}(c=0.16, \mathrm{MeOH})$. MS $m / z(\%): 413\left(\mathrm{M}^{+}+1,27\right)$, $412\left(\mathrm{M}^{+}, 100\right), 381\left(\mathrm{M}^{+}-31,40\right), 353\left(\mathrm{M}^{+}-59,20\right), 335$ (21), 251 (18), 162 (25), 161 (31), 160 (34), 69 (19), 59 (39). UV $\lambda_{\max }^{\mathrm{MeOH}} \mathrm{nm}: 216 \mathrm{sh}, 246 \mathrm{sh}, 253,287,309 \mathrm{sh}$; unchanged with $\mathrm{NaOMe}$ or $\mathrm{AlCl}_{3} .{ }^{1} \mathrm{H}-\mathrm{NMR} \delta_{\text {TMS }}^{\text {acetone-d }}(100 \mathrm{MHz})$ : 1.25 and 1.29 (both $3 \mathrm{H}$, two s, $4^{\prime \prime}$-and $\left.5^{\prime \prime} \mathrm{H}_{3}\right), 3.31(2 \mathrm{H}$, br. d, $J=c a .8 .4 \mathrm{~Hz}, 1^{\prime \prime}-\mathrm{H}_{2}$ ), 3.76, 3.83 and 3.88 (all $3 \mathrm{H}$, three s, $\left.3 \times \mathrm{OCH}_{3}\right), 4.80\left(1 \mathrm{H}\right.$, br.t, $\left.J=c a .8: 4 \mathrm{~Hz}, 2^{\prime \prime}-\mathrm{H}\right)$, $6.55\left(1 \mathrm{H}, \mathrm{dd}, J=8.3,2.4 \mathrm{~Hz}, 5^{\prime}-\mathrm{H}\right), 6.56(1 \mathrm{H}, \mathrm{s}, 8-\mathrm{H}), 6.61$ $\left(1 \mathrm{H}, \mathrm{d}, J=2.4 \mathrm{~Hz}, 3^{\prime}-\mathrm{H}\right), 7.18\left(1 \mathrm{H}, \mathrm{d}, J=8.3 \mathrm{~Hz}, 6^{\prime}-\mathrm{H}\right)$, $7.86(1 \mathrm{H}, \mathrm{s}, 2-\mathrm{H})$.
Dehydration of trimethyl-BC-I (2a.). The preceding trimethyl ether (2a, $15 \mathrm{mg}$ ) was dissolved in pyridine $(1 \mathrm{ml})$ and dehydrated by the addition of $\operatorname{SOCl}_{2}(0.1 \mathrm{ml})$ as previously described ${ }^{5)}$ to give a mixture of dehydration products. Using multi-development $(\times 3)$ PTLC $\left(\mathrm{CHCl}_{3}\right.$ : EtOAc: acetone: $\mathrm{MeOH}=50: 5: 5: 1)$, the major component $(\mathbf{1 b}, 4.1 \mathrm{mg})$ of the mixture was eventually obtained as a pure colorless gum ( $R f^{\prime} 0.74$, single run in the same solvent system) with the following properties. Gibbs test $(-) .[\alpha]_{\mathrm{D}}^{23}=-63^{\circ}(c=0.10, \mathrm{MeOH})$. MS $m / z(\%): 395$ $\left(\mathrm{M}^{+}+1.27\right), 394\left(\mathrm{M}^{+}, 100\right), 393$ (16), 379 (11), 365 (11), 364 (12), $363\left(\mathrm{M}^{+}-31,44\right), 333$ (14), 162 (15), 161 (20), 119 (11). UV $\lambda_{\max }^{\mathrm{MeOH}} \mathrm{nm}: 216 \mathrm{sh}, 246 \mathrm{sh}, 253,286,308 \mathrm{sh}$; unchanged with $\mathrm{AlCl}_{3}$ or NaOAc. ${ }^{1} \mathrm{H}-\mathrm{NMR} \delta_{\text {TMS }}^{\text {acetone- } d_{6}}$ $(100 \mathrm{MHz}): 1.79\left(3 \mathrm{H}, \mathrm{s}, 5^{\prime \prime}-\mathrm{H}_{3}\right), 3.10(1 \mathrm{H}, \mathrm{dd}, J=16.1$, $\left.7.6 \mathrm{~Hz}, 1^{\prime \prime}-\mathrm{H}_{\mathrm{a}}\right), 3.56\left(1 \mathrm{H}, \mathrm{dd}, J=16.1,9.5 \mathrm{~Hz}, 1^{\prime \prime}-\mathrm{H}_{\mathrm{b}}\right)$, 3.76, 3.83 and 3.88 (all $3 \mathrm{H}$, three s, $\left.3 \times \mathrm{OCH}_{3}\right), 4.96(1 \mathrm{H}$, br. s, $\left.4^{\prime \prime}-\mathrm{H}_{\mathrm{a}}\right), 5.13\left(1 \mathrm{H}\right.$, br. s, $\left.4^{\prime \prime}{ }^{\prime}-\mathrm{H}_{\mathrm{b}}\right), 5.41(1 \mathrm{H}$, br. t, $J=c a$. $\left.8.7 \mathrm{~Hz}, 2^{\prime \prime}-\mathrm{H}\right), 6.55\left(1 \mathrm{H}, \mathrm{dd}, J=8.3,2.4 \mathrm{~Hz}, 5^{\prime}-\mathrm{H}\right), 6.60$ $(1 \mathrm{H}, \mathrm{s}, 8-\mathrm{H}), 6.64\left(1 \mathrm{H}\right.$, incomplete d, $\left.3^{\prime}-\mathrm{H}\right), 7.18(1 \mathrm{H}, \mathrm{d}$, $\left.J=8.3 \mathrm{~Hz}, 6^{\prime}-\mathrm{H}\right), 7.87(1 \mathrm{H}, \mathrm{s}, 2-\mathrm{H})$.

$C D$ determination of osmate esters. A dry sample of each isoflavone ( $c a .1 .2 \sim 1.3 \mu \mathrm{mol}$ ) was first dissolved in $\mathrm{CH}_{2} \mathrm{Cl}_{2}(63 \mu \mathrm{l})$ containing $25 \mu \mathrm{mol}$ of pyridine, and the resulting solution was then treated with $\mathrm{OsO}_{4}(1.4 \mu \mathrm{mol}$ in $10 \mu \mathrm{l}$ of $\left.\mathrm{CH}_{2} \mathrm{Cl}_{2}\right)^{17)}$ After allowing the reaction to continue for $30 \mathrm{~min}$ at room temperature, the mixture was diluted with more $\mathrm{CH}_{2} \mathrm{Cl}_{2}$ to give a final volume of $2.8 \mathrm{ml}$. The $\mathrm{CD}$ spectrum of this solution was recorded over the range $400 \sim 600 \mathrm{~nm}$ using a Model J-20A Automatic Recording Spectropolarimeter (Japan Spectroscopic Co., Ltd.). Natural rotenone $\left(9 ; 6 \mathrm{a} S, 12 \mathrm{a} S, 2^{\prime} R\right)$ purchased as a reference compound from Nakarai Chemicals Ltd. was similarly treated with $\mathrm{OsO}_{4}$ and pyridine in molar ratios of 1.1 and 20 , respectively.

Acknowledgments. We thank Miss Y. Hatakeyama for measuring $\mathrm{FT}-{ }^{1} \mathrm{H}-\mathrm{NMR}(100 \mathrm{MHz})$ spectra, and Miss Y. Atsuta and Mr. K. Watanabe for MS analyses. Financial support (to S. T.) by a Grant-in-Aid for Scientific Research (No. 61560130) from the Ministry of Education, Science and Culture of Japan is also gratefully acknowledged.

\section{REFERENCES}

1) B. F. Burrows, N. Finch, W. D. Ollis and I. O. Sutherland, Proc. Chem. Soc., 1959, 150.

2) V. H. Deshpande, A. D. Pendse and R. Pendse, Indian J. Chem., 15B, 205 (1977).

3) F. D. Monache, G. C. Valera, D. S. D. Zapata and G. B. Marini-Bettolo, Gazz. Chim. Ital., 107, 403 (1977).

4) J. L. Ingham, Fortsch. Chem. Org. Nat.-Stoffe, 43, 1 (1983).

5) S. Tahara, J. L. Ingham, S. Nakahara, J. Mizutani 
and J. B. Harborne, Phytochemistry, 23, 1889 (1984).

6) S. Tahara, S. Nakahara, J. L. Ingham and J. Mizutani, Nippon Nôgeikagaku Kaishi, 59, 1039 (1985).

7) S. Tahara, S. Nakahara, J. Mizutani and J. L. Ingham, Agric. Biol. Chem., 48, 1471 (1984).

8) S. Tahara, S. Nakahara, J. Mizutani and J. L. Ingham, Agric. Biol. Chem., 49, 2605 (1985).

9) S. Nakahara, S. Tahara, J. Mizutani and J. L. Ingham, Agric. Biol. Chem., 50, 863 (1986).

10) M. Legrand and M. J. Rougier, "Stereochemistry: Fundamentals and Method," vol. 2, ed. by H. B. Kagan, Georg Thieme Publishers, Stuttgart, 1977, p. 58.

11) N. Sakota, T. Tanigaki, K. Okita and N. Koine, Nippon Kagaku Zasshi, 90, 593 (1969).
12) G. Buchi, L. Crombie, P. J. Godin, J. S. Kaltenbronn, K. S. Siddalingaiah and D. A. Whiting, J. Chem. Soc., 1961, 2843.

13) M. J. Begley, L. Crombie and D. A. Whiting, $J$. Chem. Soc., Chem. Commun., 1975, 850.

14) R. L. Lyne, L. J. Mulheirn and Leworthy, J. Chem. Soc., Chem. Commun., 1976, 497.

15) R. L. Lyne, L. J. Mulheirn and N. T. Keen, Tetrahedron Lett., 22, 2483 (1981).

16) J. L. Ingham and L. J. Mulheirn, Phytochemistry, 21, 1409 (1982).

17) J. L. Ingham, N. T. Keen, K. R. Markham and L. J. Mulheirn, Phytochemistry, 20, 807 (1981).

18) S. Tahara, J. L. Ingham and J. Mizutani, Agric. Biol. Chem., 49, 1775 (1985). 